\title{
Indice dei copisti anonimi
}

Anonimo A 22, 49, 64, 72-74 e n. 198, 75, 87, 91 e n. 281, 94, 96, 124, 179, 186, 190, 249 Anonimo B 22 e n. 101, n. 109, 24, 52, 64, 76-77 e n. 201, 89, 92 e n. $284,96,124$, $137,179,258,260-261$

Anonimo G 3, 19 e n. 80, 20 e nn. 86, 91 (Anonymus G) 21 e nn. 92-93, 22 e n. 101, 23-24 e n. 111,25 e n. 116, 26-27, 54, 59 e n. 152,68 e n. $165,69-71$ e n. $177,72,75,77$, 114, 115, 119, 121, 214, 216-217, 227, 243

Anonimo a 56, 59-61, 66, 114, 142

Anonimo $\beta$ 45-46, 64, 132
Anonimo $\delta$ 45-46, 64, 207-208

Anonimo \&p 65, 109, 112, 146

Anonimo $\zeta$ 52, 59, 61, 65, 111, 145

Anonimo $\mu \varepsilon v$ 60, 64, 155

Anonimo $\xi$ 52, 56, 64, 109

Anonimo tı 52, 54, 56 e n. 149, 65, 107, 109, $111,114,142,145$

Anonimo X 52, 59, 65, 107, 111, 145

Copista AG n. 200, 92, 257, 259, 261, 263

Copista del prostagma 103 e n. 349 , n. 403,248 
